\title{
Gamificação nas organizações: processos de aprendizado e construção de sentido
}

\author{
SORAIA FINAMOR NEIDENBACH ${ }^{1}$ \\ VANessa MARTINes Cepellos ${ }^{1}$ \\ Jussara Jéssica Pereira ${ }^{1}$
}

${ }^{1}$ Fundação Getulio VARgas (FGV EAESP) / Escola de AdMinistração de EMPreSAS de SÃo Paulo, SÃo PAULO - SP, BRASIL

\section{Resumo}

Este estudo apresenta uma visão dessa gamificação como possibilidade de aprendizado via construção de sentido. Para tanto, adotamos a seguinte pergunta de pesquisa: como são percebidos os processos de aprendizado e a construção de sentido da gamificação como ferramenta organizacional? A partir dos relatos de seis expertises na área e por meio da análise temática, chegou-se a dois níveis de análises: a) o nível organizacional e b) o nível individual. Tais níveis foram apresentados em três dimensões: a organização, o time/a equipe e a individual do trabalhador. Foi identificada a existência de bons resultados para os níveis organizacional e individual. Assim, destaca-se na dimensão organizacional a melhoria na produtividade, na aprendizagem e nos processos de inovação e update organizacional. Na dimensão de time/equipe, notaram-se melhorias no clima organizacional, na comunicação e no trabalho colaborativo. Na dimensão individual, houve desenvolvimento do trabalhador, autonomia, autoestima e maior transparência na relação entre líderes e liderados, bem como empoderamento.

Palavras-chave: Gamificação. Gestão. Aprendizado. Construção de Sentido.

\section{Gamification in organizations: learning processes and meaning-making}

\begin{abstract}
This study presents a view of gamification as a possibility for meaning-making learning. It analyzes the perception of learning processes and meaning-making through gamification when used as an organizational tool. Six gamification experts were interviewed, and thematic analysis was carried out, discussing the data based on two levels, organizational and individual, and three dimensions, organization, team, and worker. The interviewees perceived that gamification produces positive results at organizational and individual levels, suggesting gains in the three dimensions. As for the organizational dimension, the interviewees perceived more productivity, learning, innovation processes, and update of the organization's systems. Concerning the team dimension, there was an improvement in the organizational climate, communication, and collaborative work. Finally, in the individual dimension, the interviewees perceived worker's development, more autonomy, an increase in self-esteem, greater transparency in the relationship between leaders and followers, and empowerment.
\end{abstract}

Keywords: Gamification. Management. Learning. Meaning-Making.

\section{Gamificación en organizaciones: procesos de aprendizaje y creación de significado}

\section{Resumen}

Este estudio presenta una visión de la gamificación como una posibilidad de aprendizaje mediante la creación de significado. Para ello, adoptamos la siguiente pregunta de investigación: ¿Cómo se perciben los procesos de aprendizaje y la creación de significado de la gamificación como herramienta organizativa? De los informes de seis expertos en el área y, a través del análisis temático, llegamos a dos niveles de análisis: a) El nivel organizacional y b) El nivel individual. Dichos niveles de análisis se presentaron a través de tres dimensiones: la organización, el equipo y la dimensión individual del trabajador. Identificamos la existencia de buenos resultados para los niveles organizacional e individual. Así, se destacan en la dimensión organizacional, la mejora en la productividad, en el aprendizaje y en los procesos de innovación y actualización organizacional. En la dimensión del equipo, hubo mejoras en el clima organizacional, en la comunicación y en el trabajo colaborativo. En la dimensión individual, se observó desarrollo del trabajador, autonomía, autoestima y mayor transparencia en la relación entre líderes y seguidores, así como el empoderamiento.

Palabras clave: Gamificación. Gestión. Aprendizaje. Construcción de sentido. 


\section{INTRODUÇÃO}

Neste artigo, a gamificação é entendida como uma estratégia de aprendizagem (CAILLOIS, 2017) que se torna possível diante de várias mudanças socioantropológicas relacionadas ao modo de viver, mas, sobretudo, com o avanço do conhecimento, das tecnologias de ensino-aprendizagem e da cultura lúdica (BROUGÈRE, 1998). A área de estudos de gamificação inclui jogos, brinquedo, brincadeira e ludicidade, mantendo, ainda, interface com outros temas, tais como fantasia, imaginação, ócio e lazer (FORTUNA, 2017). A amplitude temática acena para várias possibilidades de intersecções, mas, especificamente neste artigo, analisa-se essa ferramenta aplicada ao contexto de gestão.

Os videogames e o ambiente virtual têm sido estudados sob diversas perspectivas. Entre elas, há aquelas que utilizam a gamificação para melhorar a maneira pela qual as empresas engajam clientes e empregados (ROBSON, PLANGGER, KIETZMANN et al., 2016) como estratégia para aprimorar a gestão de risco em um negócio (Bajdor \& Dragolea, 2011), em processos de inovação empresarial (SHPAKOVA, DÖRFLER e MACBRYDE, 2020), como ferramenta de ensino e aprendizagem em gestão a partir da Classcraft platform (SANCHEZ, YOUNG e JOUNEAU-SION, 2017) e até mesmo para intervenções de saúde no controle de doenças (THENG, LEE, PATINADAN et al., 2015).

A literatura em games and management está, em sua maior parte, preocupada em melhorar processos e desempenhos usando uma experiência anterior via gamificação. Isso porque uma das suas maiores vantagens é prever situações e potenciais conflitos e sua resolução antes que eles possam acontecer no mundo real. Entendida como uma ferramenta para desenhar comportamentos, desenvolver habilidades e, consequentemente, possibilitar processos de inovação, a gamificação, quando combinada com outras tecnologias, pode favorecer a performance dos funcionários, a aprendizagem e o desenvolvimento do engajamento do cliente (BURKE, 2012). A pertinência e o interesse na gamificação aplicada ao contexto de gestão vêm aumentando em decorrência da utilização de metodologias de simulações empresariais, como a aprendizagem baseada em projetos (ABP). Tais simulações são capazes de incentivar a formação de profissionais com capacidade de autoquestionamento e o desenvolvimento do pensamento sistêmico (VERSIANI e FACHIN, 2007). Além disso, consistem em uma estratégia de ensino pela qual os aprendizes têm oportunidade de resolver problemas, tomar decisões e fazer tarefas complexas e desafiadoras, com impactos positivos nos processos e resultados de aprendizagem (GÓMEZ-PABLOS e MUÑOZ-REPISO, 2019). Progressivamente, tais conceitos vêm dando bases a novas pedagogias e didáticas nas organizações.

Para Caillois (2017), a palavra "jogo" sugere a ideia de liberdade útil, tornando a mobilidade um quesito indispensável. Assim, o jogo subsiste entre os diversos mecanismos que permitem o funcionamento eficaz de uma estrutura. No contexto das organizações, essa liberdade útil dos jogos é determinada pelo seu caráter pedagógico e lúdico, uma vez que contribui para o aprendizado dos funcionários e o bom funcionamento organizacional. Embora se note a presença e a contribuição de estudos que abordam a questão da aprendizagem em simulações empresariais (VERSIANI e FACHIN, 2007) e jogo e educação (BROUGÈRE, 1998, 2002), uma lacuna ainda se mantém quando consideramos a gamificação como ferramenta de ensino e aprendizagem.

Diante disso, este artigo traz uma contribuição ao campo de gestão, entendendo a gamificação como estratégia de ensino-aprendizagem, construção de sentido e acumulação de experiências anteriores. Para tanto, tem como pergunta de pesquisa: como são percebidos os processos de ensino-aprendizagem e de construção de sentido na implementação da gamificação como ferramenta organizacional? Como objetivos geral e específíco, respectivamente, buscou-se: I) analisar nos níveis organizacional e individual os impactos percebidos na implementação da gamificação; II) descrever critérios de aprendizagem nas intersecções entre as dimensões relacionadas à organização, ao time/equipe e ao indivíduo. A fim de compreendermos a questão necleadora, entrevistamos seis expertises na área. Os dados foram submetidos à "análise temática".

A gamificação, assim como os jogos de treinamento corporativo, compreende mecanismos para a resolução de problemas de gestão e eficiência operacional e aumento da produtividade empresarial (DEWINTER, KOCUREK e NICHOLS, 2014). Tal pressuposição pode explicar o crescente interesse de gestores e pesquisadores em pensar a prática dos negócios de modo inovador, atrativo e engajador (ROBSON, PLANGGER, KIETZMANN et al., 2015). A gamificação corresponde ao uso de mecanismos de jogos com o objetivo de resolver problemas práticos ou de despertar o engajamento de um público específico e, sobretudo, agilizar processos de aprendizado ou de treinamento, tornando mais agradáveis tarefas tediosas ou repetitivas (VIANNA, VIANNA, MEDINA et al., 2014). 
Com o aumento das possibilidades de acesso à informação, as pessoas, independentemente do dispositivo que usam ou do local onde estejam, têm a oportunidade de aprender e estudar a qualquer momento e em qualquer lugar porque as tecnologias móveis que usam diariamente são cada vez mais cloudbased (JOHNSON, ADAMS e HAYWOOD, 2011). Nesse sentido, a tecnologia tem mudado o modo como o universo corporativo se conecta e organiza, estruturando novos modelos, espaços e projetos. O modelo digital proporcionado pela gamificação vai além das interações face to face, quebrando os padrões tradicionais de tempo, distância, despesa e conectividade.

Além desta introdução, o artigo apresenta o referencial teórico explorando a definições de gamificação, a implementação da gamificação e os resultados esperados. Em seguida, são apresentados os procedimentos metodológicos, seguidos de análise e discussão dos resultados e, então, as considerações finais.

\section{REFERENCIAL TÉORICO}

\section{Gamificação e aprendizagem}

Tecnologia, dispositivos móveis, redes sociais e toda a lógica baseada na World Wide Web (WEB) mudaram significativamente a maneira pela qual o trabalhador e a organização se relacionam. Em termos de aprendizagem, essa mudança tem acompanhado os crescentes avanços tecnológicos de uma economia baseada na informação (BELTRÃO e BARÇANTE, 2019). Esse cenário em que as organizações vêm atuando nas últimas décadas é denominado era do conhecimento (CASTELLS, 1999) e se caracteriza por uma profunda transformação de acesso ao conhecimento e produção dele por meio da Internet. Assim, nas organizações contemporâneas, aprender, reaprender, desaprender, adaptar, inovar e mudar, analisar, imitar, renovar, automatizar e tecnologizar tornaram-se os principais componentes de qualquer esforço organizacional (NOGUEIRA e ODELIUS, 2015).

Pesquisas recentes têm demonstrado que, no que tange ao aprendizado, as organizações precisam compreender não apenas o modo como o processo de aprendizagem ocorre, mas, sobretudo, os aspectos que influenciam o conhecimento (ODELIUS, ABBAD, RESENDE JUNIOR et al., 2011). Entendendo o game e toda a sua característica lúdica no processo de produção do conhecimento (D’ÁVILA, 2014; LUCKESI, 2005), exploram-se neste artigo as intersecções entre aprendizagem e gamificação nas organizações.

As primeiras referências sobre jogos surgiram na década de 1980, com Richard Bartle, por meio da palavra gamificando (do inglês gamifying), que significa: "Tornar algo não jogo em jogo". O primeiro emprego do termo gamificação foi feito em 2003 pelo desenvolvedor britânico Nick Pelling e depois ficou adormecido até que pesquisadores de jogos o fizeram ressurgir em meio a discussões a respeito dos potenciais benefícios do vídeo game (WERBACH e HUNTER, 2012). Alves (2015) conceitua gamificação como "pensamento de jogos", que consiste em converter uma atividade cotidiana em uma atividade que contenha elementos de jogo, entre os quais competição, cooperação, exploração, premiação, storytelling etc.

O jogo é um fato social importante da cultura contemporânea, uma vez que consiste na manipulação de imagens que representam uma determinada realidade (HUIZINGA, 1971). Além disso, ele permite a valorização das diversas dimensões do aprendizado por meio de seu efeito lúdico (BROUGÈRE, 2002). A ideia de aprendizagem organizacional aponta para o aproveitamento das energias emocionais positivas provenientes do "aprendizado em ação" (GARRATT, 1999; REVANS, 1982). Para Argyris e Schön (1978), essa aprendizagem ocorre quando indivíduos da organização experimentam uma situação problema e começam a investigá-la. Ao experimentar uma incompatibilidade entre os resultados esperados e os reais da ação, os indíviduos respondem por meio de um processo de pensamento que os leva a modificar as imagens que eles têm sobre a organização, bem como seus entendimentos sobre os fenômenos organizacionais. Tal feito leva os indivíduos a reestruturarem suas atividades para corresponder aos objetivos esperados, alterando assim o processo organizacional em uso (WANG e AHMED, 2003).

Nesse cenário, a gamificação passa a representar mecanismos e ferramentas capazes de apresentar alternativas tangíveis para lidar com o aprendizado e para sugerir um novo modo de enxergar as relações de trabalho (VIANNA, VIANNA, MEDINA et al., 2014). A gamificação coloca em jogo a questão da individualidade inserida no sistema de jogo, considerando os sentimentos das pessoas, suas inseguranças e as razões pelas quais querem ou não fazer algo, para então otimizar esses sentimentos, motivações e estimular o engajamento (CHOU, 2013). Consequentemente, a gamificação tem se tornado um elemento cada 
vez mais popular em diversos ambientes, demonstrando resultados positivos na motivação de equipes no setor privado (VENTRICE, 2009).

Ao contrário de outras técnicas usadas pela área de recursos humanos, a gamificação estimula e desperta o sentimento de conquista (MARRAS e TOSE, 2012) - por exemplo, aspectos ligados à avaliação de desempenho podem ser notados após a implementação da ferramenta. Nesse sentido, o progresso dos participantes é instituído com critérios claros e objetivos, promovendo uma maneira de avaliar a performance sem o "peso" dos processos convencionais que atualmente, em sua maioria, são aplicados em datas específicas, gerando ansiedade, estresse e insegurança nos profissionais avaliados.

A gamificação é o ofício de pegar os elementos de diversão e engajamento dos jogos convencionais e aplicá-los às atividades produtivas (CHOU, 2013). Consiste no uso do design de experiências digitais de jogos para motivar e engajar pessoas no alcance de objetivos (BURKE, 2015; GARTNER, 2011). A definição da estratégia ainda inclui: 1) mecânica de jogos e seus elementoschave como pontos, distintivos e placares; 2 ) design de experiência digital representada pela jornada que os jogadores terão de percorrer, como descrição do jogo, passo a passo, reconhecimento do ambiente e decodificação do roteiro; 3 ) métodos para engajar indivíduos virtualmente por meio de computadores, tablets, smartphones e outros dispositivos digitais; e 4) motivação de pessoas e comportamentos pró-utilização de tecnologias, estimulo à inovação e desenvolvimento de habilidades. Burke (2015) afirma que a gamificação potencializa, tanto nos jogadores quanto nas organizações, o alcance de objetivos.

Ao usar games, o trabalhador é desafiado a realizar determinado comportamento preestabelecido, recebendo como retorno uma recompensa que Ihe faça sentido. É necessário um trabalho motivacional com o funcionário que resulte em engajamento com a meta estabelecida e benefício mútuo para ele e para a empresa. Outra vantagem refere-se à abrangência da gamificação, já que pode contribuir para a socialização da informação, possibilitando atingir diferentes gerações e superar a delimitação física (BURKE, 2015). A ferramenta e seu potencial para aprendizagem organizacional dependem da implementação e desenho dos jogos, como demonstrado a seguir.

\section{Implementação da gamificação}

Segundo Alves (2015, p. 27), é necessário desenhar um sistema de gamificação que estimule o engajamento, similar a "um desafio abstrato, definido por regras claras, interagindo e aceitando feedback, com o alcance de resultados quantificáveis e com a presença de reações emocionais". Tal desenho precisa levar em conta, em primeiro lugar, se a gamificação é a resposta para os problemas que a organização enfrenta. Muitas vezes, as pessoas estão mais "enfeitiçadas" por uma tendência do que apontando soluções eficientes para seus problemas (BURKE, 2015). A fim de evitar que esse engano ocorra, o primeiro passo para a construção do desenho gamificado é analisar os objetivos da empresa.

Para avaliar se a gamificação é, de fato, a ferramenta que pode auxiliar a organização, é preciso atentar para alguns aspectos do processo de planejamento. Definição do público-alvo, ou seja, quem o método projetado pretende atingir. Definição dos objetivos que os jogadores terão, em alinhamento com os objetivos da empresa, que foram apontados no início do planejamento. Determinação do modelo de engajamento dos jogadores - é importante que haja a utilização de elementos sociais e que o desenho promova a cooperação acima da competição. Definição do ambiente de jogo e da jornada a ser percorrida, suas ações e seus ciclos de engajamento. Definição dos incentivos e das recompensas e, por fim, teste e repetição do jogo, uma vez que "o design de experiência gamificado deve construir soluções de baixo para cima" (BURKE, 2015, p. 84). Dessa forma, faz-se necessário uma conexão incessante entre o projeto e a realidade dos jogadores (SANTINHO, 2018). Isso é importante uma vez que a brincadeira pode despertar emoções, linguagens e conversas (MATURANA e VERDEN-ZÖLLER, 2004) diretamente relacionadas ao aprendizado grupal, individual e organizacional. $O$ design da gamificação não pode se limitar às tecnicidades das ferramentas a serem utilizadas ou dos elementos do jogo, mas deverá oferecer uma jornada integrada às necessidades das pessoas, bem como possibilidades tecnológicas e requisitos para o sucesso da experiência (BURKE, 2015; SANTINHO, 2018).

O êxito da gamificação depende simultaneamente da coerência e do alinhamento dos aspectos envolvidos no jogo, como emoções, dinâmicas e recompensas (ROBSON, PLANGGER, KIETZMANN et al., 2016). Técnicas de engajamento também são feitas e auxiliam tanto no sucesso da implementação dos jogos quanto no aspecto lúdico. Assim, o desenvolvimento do profissional torna-se um momento divertido, recreativo e produtivo. Tal feito aproxima o humano de sua infância, explorando uma ligação profunda entre o amar e o brincar (MATURANA e VERDEN-ZÖLLER, 2004). 
A gamificação é um método para engajar indivíduos digitalmente em vez de pessoalmente (BURKE, 2015). Seu objetivo é motivar a pessoa a alterar seus comportamentos, desenvolver habilidades ou estimular a inovação. Seu uso reflete a iniciativa de organizações que buscam a capacitação e o atingimento de metas de maneira atrativa, a fim de incentivar os comportamentos necessários para alcançar os objetivos e ampliar o desenvolvimento dos seus negócios. Os objetivos da gamificação vão de alcançar níveis mais altos de engajamento a mudar comportamentos e estimular a inovação (GARTNER, 2011).

A seguir, são descritos os aspectos concernentes aos métodos usados nesta pesquisa.

\section{PROCEDIMENTOS METODOLÓGICOS}

De caráter qualitativo e exploratório, o presente estudo realizou seis entrevistas semiestruturadas com consultores de gamificação que já implementaram a ferramenta no setor varejista. As entrevistas tiveram duração de 1 hora e meia, em média, e foram realizadas de duas formas: presencial e por Skype. Os áudios coletados foram transcritos para posterior análise. Optou-se pela preservação da identidade dos participantes usando as nomenclaturas E1, E2, sucessivamente, para citação dos entrevistados, conforme pode ser visto no Quadro 1, em que são apresentados os sujeitos da pesquisa.

\section{Quadro 1}

Sujeitos de pesquisa

\begin{tabular}{|c|c|c|}
\hline Entrevistados & Cargo & Cenário da utilização \\
\hline E1 & Consultor sênior & Gerenciamento de performance \\
\hline E2 & Gestora de recursos humanos & Gerenciamento de performance e clima organizacional \\
\hline E3 & Diretora & $\begin{array}{c}\text { Gerenciamento de performance, clima organizacional } \\
\text { e ferramenta de aprendizagem }\end{array}$ \\
\hline E4 & Coordenador de mudanças organizacionais & Ferramenta de aprendizagem (treinamento) \\
\hline E5 & Analista sênior tecnologia \& Desenvolvimento & Ferramenta de aprendizagem (treinamento) \\
\hline E6 & Gerente executivo/produtos e Bl & Gerenciamento de performance \\
\hline
\end{tabular}

Fonte: Elaborado pelos autores.

O contexto desta pesquisa está relacionado à presença da gamificação nas organizações. Os entrevistados selecionados caracterizam-se por serem responsáveis pela liderança da implementação e pelo acompanhamento da ferramenta em organizações varejistas. Os varejistas entrevistados que implantaram a gamificação como solução de aprendizagem a entendem como solução inovadora e estimulante de aprendizagem de conteúdo (treinamento), que proporciona ganhos em escala e apresenta menor custo de implementação.

A coleta de dados foi efetuada pela primeira autora, também responsável pelo contato inicial e seleção dos respondentes. Durante a coleta de dados, foram apresentados dois cenários, o primeiro relacionado ao gerenciamento da performance da equipe e o segundo como solução de aprendizagem organizacional e individual. Quanto às questões, totalizaram 15 (quinze), com flexibilidade para colocações que os sujeitos de pesquisa declarassem importantes. O roteiro semiestruturado foi enviado antecipadamente aos entrevistados, juntamente com o termo de consentimento de participação. Com os dados coletados e transcritos, optou-se pelo método de análise temática, com objetivo de compreendê-los, descrevê-los e interpretá-los.

Todo o material analisado foi decorrente das entrevistas realizadas. A análise temática é um processo de identificação de padrões e temas com dados obtidos em uma pesquisa qualitativa. O objetivo desse método é identificar temas, ou seja, padrões nos dados que sejam relevantes para os objetivos da pesquisa, e, a partir deles, compreender aspectos do objeto estudado. Para realizá-lo, existem seis etapas fundamentais.

A primeira visa a tornar o pesquisador familiar com os dados. Consiste em ler e reler as transcrições - é importante que o pesquisador esteja familiarizado com todo seu corpus de dados. A segunda etapa consiste na primeira codificação do material transcrito com vistas a organizar os dados de maneira sistêmica, o que permite organizar um volume grande de dados em 
pequenos grupos de sentidos. A terceira engloba a busca por temas, considerando-se como tal o padrão que captura algo significante ou interessante sobre um dado ou alguma questão de pesquisa. Os códigos da etapa anterior podem ser agrupados em temas amplos que se alinhem a questões específicas. Já na quarta etapa, os códigos temáticos apontados na segunda etapa são revisados. É o momento de verificar se a codificação realizada está coerente com o plano geral dos dados coletados e da pesquisa como um todo. Os temas devem ser coerentes e distintos uns dos outros. A quinta etapa propõe um refinamento para identificar a essência das temáticas, mostrando a necessidade de compreender o que cada tema está dizendo, se há subtemas e como integrá-los, e como eles se relacionam. Por último, o sexto passo é destinado à escrita das descobertas. A seguir são apresentados os dados e as discussões (MAGUIRE e DELAHUNT, 2017).

Sobre a triangulação das análises, após uma primeira rodada de análise efetuada pela primeira autora, as pesquisadoras reuniram-se para discutir os resultados. Por meio de um processo iterativo, a segunda e a terceira autoras também analisaram o material das entrevistas separadamente e apresentaram suas análises. Os resultados de todos os pesquisadores foram contrastados, observando-se comunalidades e padrões e garantindo plausabilidade às interpretações. Percebeu-se três dimensões temáticas na análise dos dados.

Sobre o desenho das análises e confiabilidade, a partir de um processo iterativo de pesquisa, houve um caminho circular entre dados e conceitos apresentados no referencial teórico (MERRIAM, 2002; STRAUSS e CORBIN, 1998).

\section{ANÁLISE DOS DADOS}

A partir da análise temática, chegou-se a dois níveis de análises. São eles: a) o nível organizacional e b) o nível individual, por sua vez divididos em três dimensões, a da organização, a do time/equipe e a individual. Estas, por sua vez, não são excludentes entre si, mas complementares umas às outras, embora a dimensão intermediária (time/equipe) seja a que apresente maior contato com as outras duas.

Na análise temática, a codificação é feita de modo aberto. Assim, percebeu-se que os sujeitos de pesquisa falavam em aprendizagem via gamificação em dois sentidos: 1) a partir da perspectiva organizacional ou corporativa; e 2) a partir da perspectiva do indíviduo ou trabalhador. A partir daí, os dados foram separados em dois grandes conjuntos: "organização" e "indivíduo", que constituem dois níveis de análise, uma vez que apresentavam elementos diferentes. Por exemplo, os sujeitos de pesquisa, ao relatarem as principais mudanças após a gamificação, tendiam a separar as duas dimensões: "na organização se percebeu um aumento/diminuição de X", já no "funcionário percebeu-se a mudança de comportamento Y". Os benefícios da gamificação, por outro lado, eram percebidos tanto nos conjuntos "organização" e "indivíduo" como na sua intersecção com "time/equipe", estes nomeados, conforme já mencionado, como dimensões.

A seguir, detalha-se cada tema proposto.

\section{Dimensão organizacional}

Entendendo a gamificação como uma aliada organizacional, os entrevistados enfatizaram o uso da ferramenta como solução dinâmica, inovadora e estimulante para despertar o interesse do funcionário (VENTRICE, 2009). Eles reconheceram que o game em si precisa ser trabalhado conjuntamente com outros elementos de gestão para que a experiência seja rica e válida tanto para o funcionário quanto para a empresa. Assim, o trabalhador tem a oportunidade de se desenvolver, sendo uma ferramenta de treinamento menos onerosa para a empresa, visto que o processo gamificado pressupõe um investimento menor em relação ao treinamento presencial.

Não é só um game técnico para mudança de sistema que iria facilitar o processo dentro da loja. Além da parte do processo para melhoria contínua dentro da atividade, existia também todo um trabalho voltado para fortalecer os valores e gerar um engajamento [E4].

A partir dessa fala, foi possível perceber a existência de dois níveis de análise, a organizacional e a individual, na percepção da gamificação. Isso pode ser observado diante dos termos "Ioja", que indica algo mais estrutural, e "trabalho", que implica algo mais individual. Ademais, quando esses dois níveis se relacionam, eles podem ser explicados a partir de três dimensões: organização, time/equipe e trabalhador. Quando o entrevistado relata que "existia (...) todo um trabalho voltado para fortalecer 
valores e gerar um engajamento", é possível a interpretação de que a mudança relacionada ao processo de gamificação requer integração, comunicação e cocriação entre a organização, o trabalhador e sua equipe.

No que tange à dimensão organizacional, a análise da fala dos entrevistados dá a perceber que a motivação pela busca do uso dessa ferramenta está relacionada à inovação e ao update dos sistemas da organização, bem como ao engajamento, motivação, estímulo e desenvolvimento de habilidades necessárias ao dia a dia da empresa (BURKE, 2015).

O sistema estava antigo e obsoleto... a gente tinha que desenvolver uma plataforma de aprendizado gamificada que contemplasse os 10 mil colaboradores; destes, 9 mil colaboradores são de lojas e mais ou menos 800 colaboradores, de serviços internos, que é a matriz [E4].

Nessa fala, por exemplo, o termo "sistema" leva à interpretação de elementos vinculados mais à estrutura de nível organizacional do que à individual. Assim, a implementação da gamificação como ferramenta de aprendizagem organizacional estava em consonância com pesquisas que demonstram que os games são bem-vistos pelos pesquisadores em educação (DOMíNGUEZ, SAENZ-DE-NAVARRETE, DE-MARCOS et al., 2013) porque se configura- um entretenimento que envolve as pessoas em atividades interativas dentro de um processo ativo de aprendizagem (KOSTER, 2013). Ademais, os jogos podem promover um contexto fictício em forma de narrativas, imagens gráficas e música, encorajando os jogadores em outros tópicos não games (WATSON, MONG e HARRIS, 2011).

Vamos pensar em um game, vamos partir para o on-line, porque a gente ganharia em financeiro e em agilidade; e também, já que a gente está indo nessa pegada, vamos nos modernizar, vamos modernizar a forma de aprendizagem, porque hoje em dia várias empresas estão usando a gamificação. $\mathrm{E}$ foi por isso que a gente optou [E4].

Os entrevistados reforçaram a importância da ferramenta de gamificação para uma organização com mais de 23 mil trabalhadores, pois, além de facilitar a aprendizagem, perceberam que a ferramenta trazia benefícios para o fomento da produtividade. Contudo, a estratégia corporativa deveria estar alinhada à constante busca por inovação, ou seja, como forma de agilizar seus processos de aprendizado (VIANNA, VIANNA, MEDINA et al., 2014).

A questão da gamificação foi um adendo, uma nova roupagem, a cereja do bolo (...). Também estamos usando a técnica da gamificação sem utilizar a plataforma, como uma metodologia para criar um ranking para gerar mais produtividade entre os funcionários [E5].

Nessa perspectiva, Burke (2015) aponta a existência de muitas vantagens no uso de um modelo digital, como: escala e distância, já que as interações dessa natureza podem conectar públicos de quaisquer tamanhos e lugar; tempo, já que independem de outras pessoas estarem disponíveis em tempo real; e custo, uma vez que as interações digitais custam bem menos que as efetivas.

A primeira vez nós recebemos um comentário da nossa ouvidoria foi, sabe o quê? "O Senhor X é incrível, porque ele me pergunta todo dia como é que eu estou me sentindo". Ele [o funcionário] se sentiu visto. Do ponto de vista da gamificação, [foi] o que a gente o trouxe aqui para dentro [E3].

A gamificação oferece uma forma de motivação em que o contato pessoal é substituído por um modelo de envolvimento digital (BURKE, 2015). Do ponto de vista da promoção do sentimento de pertencimento e transparência junto aos funcionários, as plataformas de jogos digitais podem favorecer essa percepção sem que necessariamente isso aconteça no tempo real do funcionário, mas no tempo disponibilizado pela plataforma.

\section{Dimensão da equipe ou time}

Entendendo a gamificação como aliada simultaneamente da organização e do trabalhador, no que tange à dimensão da equipe/ time, é importante ressaltar que seu processo pode auxiliar na organização de grupos, indentificando habilidades e fraquezas e combinando esses elementos em um time ou grupo equilibrado (ZICHERMANN e CUNNINGHAM, 2011). Ainda, pode se caracterizar como um processo para criar simetria entre as habilidades dos indivíduos que compõem a equipe. De acordo com as entrevistas, os principais apontamentos para a utilização da gamificação devem-se a dois cenários: gerenciamento da performance da equipe e como solução de aprendizagem corporativa (SANTINHO, 2018). A gestão de clima alinhada à performance também foi apontada pelas consultorias entrevistadas. Nesse sentido, um dos principais fatores que justificam 
todo o interesse despertado pelos jogos diz respeito à percepção de sua atratividade, refletida também na capacidade de gerar engajamento e dedicação no contexto corporativo (VIANNA, VIANNA, MEDINA et al., 2014).

Meu cliente disse: "A gente precisa escancarar esse novo modelo de comissionamento, deixando de uma forma mais divertida, vinculando a performance com a comissão, e tal (...), renovando a cultura" [E1].

Percebe-se que o processo de desenho da ferramenta de gamificação nas organizações entrevistadas iniciou-se com reuniões entre a consultoria, a alta gestão e as demais áreas envolvidas, para definição e alinhamento das expectativas da equipe sobre a ferramenta. Visto que "o design de experiência gamificado deve construir soluções de baixo para cima" (BURKE, 2015, p.84), a maior parte dos entrevistados ressaltou a importância de consultar todas as áreas envolvidas nessa etapa de elaboração. Eles usaram intranet, e-mail marketing e palestras de sensibilização que destacavam a importância da participação de todos para o sucesso da ferramenta.

A colaboração e o trabalho em equipe são elementos constantemente empregados nos games. Assim, os profissionais mais assíduos em relação às sugestões dadas podem ser reconhecidos por plataformas digitais orientadas à finalidade não só de rastrear as atividades, mas de indicar novas oportunidades de contribuição, promovendo a motivação intrínseca a partir do reconhecimento público. A ideia de tangibilizar iniciativas, ou mesmo permitir que assumam contornos mais lúdicos (HUIZINGA, 1971) por meio de elementos provenientes dos jogos, pode vir a despertar a competitividade positiva, gerando comprometimento espontâneo no desempenho de tarefas pouco estimulantes ao intelecto (VIANNA, VIANNA, MEDINA et al., 2014).

A gamificação foi estimulada não para gerar uma competição entre as pessoas, mas para gerar uma colaboração entre as pessoas. Colaborar é legal e colaborar vale pontos [E3].

As diretrizes do jogo contribuíram para estabelecer determinados pontos - por exemplo, o aspecto de cooperação entre os jogadores (ALVES, 2015). Após a definição clara do problema a ser sanado, do contexto envolvido, do entendimento dos objetivos de negócio, do perfil dos jogadores e da missão determinada, o formato do jogo foi definido, sendo composto de: tema, história e estética. Ao passo que a ferramenta de gamificação foi adquirida para estimular a aprendizagem e as habilidades do colaborador, nota-se pelos entrevistados o engajamento do funcionário. Seu envolvimento, sua motivação e a diminuição do turnover foram fatores apontados pelos entrevistados ao abordarem os motivos pela busca de uma ferramenta gamificada.

A gente buscou a gamificação para realmente diminuir o turnover e deixar a comissão mais atrativa para o pessoal [E2].

Foram apontadas também melhoria no clima organizacional, premiação e sentimento de reconhecimento do funcionário pela organização (ALVES, 2015). Um dos consultores sêniores relatou um aumento de 15\% a 20\% de faturamento e engajamento. Com relação ao turnover, ele apontou uma redução de $50 \%$ em uma das operações que gerenciou. Já a gestora de mudanças de um dos varejistas com 10 mil colaboradores relatou que a plataforma de gamificação para aprendizagem obteve inicialmente $88 \%$ de engajamento com sucessão progressiva.

Os entrevistados mostraram-se envolvidos pelo contexto simbólico do formato do jogo. Notou-se a construção de significados relacionados à aprendizagem, bem como às práticas engajadoras de gestão, tanto ao discorrerem sobre as regras e os objetivos quanto ao tratarem do reconhecimento pela empresa do esforço do empregado. As histórias usadas nesses contextos simbólicos retratados pelos entrevistados eram apresentadas, em sua maioria, como uma sequência de eventos que representavam fielmente as atividades a serem desempenhadas. Um potencial engajamento tornava-se perceptível à medida que o funcionário era convocado pelo jogo a passar sempre para a próxima etapa. Depreende-se daí que o design e a estética dos jogos consolidam ainda mais a experiência. Com relação à duração do jogo, foram notadas variações conforme a necessidade da empresa.

A gente percebe que essa comunicação alinhada tem favorecido bastante o engajamento (...). Toda quartafeira temos conteúdo em destaque da semana, conteúdo livre voltado à cultura digital, ferramentas ágeis, feedback, experiências de vendas. São pílulas do conhecimento rápidas e objetivas; isto favoreceu o engajamento para conhecer a ferramenta [E5]. 
Um efeito positivo do engajamento proporcionado pela gamificação é o treinamento. A complexidade de alguns dos jogos oferece uma excelente educação em habilidade de liderança e trabalho em equipe (ISMAIL, VAN GEES e MALONE, 2018). Com relação à aprendizagem, o modelo cooperativo é muito utilizado em jogos corporativos, nos quais as pessoas cooperam em torno de um objetivo comum, trabalhando juntas para a conquista de recursos e objetivos (ALVES, 2015). Esse modelo reflete a preocupação da empresa de promover uma comunicação clara junto aos colaboradores, bem como de estimular a atuação em equipe, compartilhando informações.

\section{Dimensão individual}

Ao analisar a gamificação e todo seu potencial para o desenvolvimento pessoal do jogador (MATURANA e VERDEN-ZÖLLER, 2004), observa-se uma dimensão de aprendizado individual. Conforme identificado nas entrevistas, a ferramenta deve estar de acordo com as expectativas e necessidades reais do jogador para garantir seu envolvimento e, assim, um maior aprendizado.

Este é um dos pilares da gamificação: entender qual é o objetivo das pessoas para alinhar ao objetivo da empresa. Cabe ressaltar que a gamificação não caminha sozinha; a estratégia de comunicação se faz necessária. Não é um joguinho, as pessoas não estão ali para perder tempo [E1].

É necessário que haja o levantamento do perfil dos funcionários para a construção da persona e para compreender as motivações extrínsecas e intrínsecas do público-alvo e o tipo de jogador que será envolvido. A falta de interesse e motivação é uma das causas da má performance dos profissionais empresariais. Diante disso, pesquisadores comportamentais tentam criar soluções que engajem os profissionais em suas atividades diárias para que eles alcancem melhores resultados (CHOU, 2013; ROBSON, PLANGGER, KIETZMANN et al., 2015).

A gente envolve as pessoas numa estratégia antes de chegar com a solução pronta. Elas começam a se sentir parte daquilo que está acontecendo e, aí, o envolvimento aumenta absurdamente [E1].

Personas são criadas a partir de comportamentos observados em campo e apresentam certas características demográficas, comportamentais e relacionadas às suas atividades. Por exemplo, gerações diferentes possuem padrões distintos de comportamento (POOLE, KEMP, PATTERSON et al., 2014). A geração baby boomer identifica-se com competição e sistemas hierárquicos. Já a geração X é pragmática, individualista, não permite fracasso. A geração Y cresceu convivendo com vídeogames e Internet, apresentando a necessidade de feedback imediato; ela adota um comportamento mais colaborativo e aprende fazendo (POOLE, KEMP, PATTERSON et al., 2014; VIANNA, VIANNA, MEDINA et al., 2014).

A gente precisa conhecer e entender o perfil das pessoas, não só no trabalho, mas também fora; e a melhor forma é conversando e perguntando (...). Perguntar sobre o que gostam, entender o contexto da pessoa, o que pensa sobre a empresa, o que motiva e desmotiva, quem são as pessoas mais engajadas e desengajadas e por quê [E1].

Todas essas características são imprescindíveis para o desenho e a implementação da ferramenta de gamificação. Um dos varejistas entrevistados apontou a necessidade de avaliar a familiaridade dos funcionários com o universo digital, de modo que se pudesse compreender qual seria a melhor maneira de fazê-los aderir à ferramenta.

No início fizemos uma pesquisa de uso digital, perguntando para eles o quanto eles usavam a internet; e a resposta foi: uso para banco, Facebook, Instagram, para chamar táxi. Então a gente descobriu que a maioria usava muito mais para operações complexas, como pagamento de contas. A gente se surpreendeu com a pesquisa [E4].

Todos os entrevistados mencionaram aspectos positivos identificados pela liderança do RH, como o aumento do engajamento da equipe devido à clareza com a qual as informações foram apresentadas pela plataforma gamificada, aumento do sentimento de pertencimento e empoderamento dos funcionários, além de autonomia, autoestima e até mesmo maior transparência na relação entre líderes e liderados.

A central de trocas é um e-commerce baseado no conceito de estoque, eu coloco lá tanto day offs (...). Só que (...) eu não dou um day off para uma pessoa; essa pessoa compra um day off porque está disponível na central de trocas. Então, por meio da gamificação, a gente quebrou um pouco desse conceito de hierarquia e poder: "O poder é meu, sou eu que performo, eu que atinjo a quantidade de coins necessários para fazer uma troca; e sou eu que realizo essa troca" [E3]. 
Observa-se o rompimento dos modelos tradicionais de gerenciamento, com enfoque na hierarquia. Segundo Vianna, Vianna, Medina et al. (2014), em grandes corporações é comum notar um sentimento de frustração generalizado decorrente do não entendimento do que é necessário para ascender profissionalmente. Nesse sentido, a gamificação pode ser de grande valia ao sugerir que departamentos definam missões específicas e critérios transparentes para a evolução dentro da empresa.

O que é o Amigo Anjo? O que a gente fez? Se o cara for uma "estrela", ele, teoricamente, pode apadrinhar alguém, e aí isso também é gamificável. O que significa apadrinhar alguém? Eu tenho que dar dicas para ela, eu tenho que ajudá-la a ser mais assertiva em um atendimento ou oferecer o mix de produto ideal para ela atingir aquele resultado. Sabe aqueles atalhos? É uma forma que um amigo, um par dele, igual a ele, só que ele é um "G1", eles têm funções idênticas, mas eles têm performances diferentes. Então, como que eu gamifiquei? Pessoas de funções idênticas, porém, com performances diferentes podem ser reconhecidas à medida que eles ajudarem os colegas que estão com performance abaixo [E3].

Em termos de aprendizagem, quando pensamos em gamificação, estamos em busca da produção de experiências que sejam engajadoras e que mantenham os jogadores focados em sua essência para o aprendizado de algo que impacte positivamente sua performance (ALVES, 2015).

Quanto às etapas envolvidas durante a implementação da ferramenta, cabe pontuar que elas diferem entre os varejistas em virtude da dinâmica e da cultura da empresa, do corpo diretivo, do objetivo final e da consultoria contratada. $O$ "fator humano" foi de extrema importância no processo de implantação e adesão, contribuindo, consequentemente, para o sucesso da ferramenta gamificada. Compete mencionar a fase "pós-game" utilizada por um dos entrevistados (E4). Após a conclusão do jogo, a empresa ofereceu aos trabalhadores um ambiente chamado "bolha", também conhecido por ambiente de degustação. Trata-se de um PDV, um caixa fictício, no qual o funcionário pode treinar a atividade a ser desempenhada. A seguir são apresentadas as contribuições das análises para o entendimento da gamificação nas organizações.

\section{DISCUSSÃO}

Esta pesquisa visa a contribuir com a literatura de gamificação nas organizações, associando o jogo ao seu caráter educativo e lúdico (BROUGÈRE, 1998). Explorou-se a ligação entre o game e a aprendizagem organizacional, propondo que a ferramenta seja vista como uma estratégia de aprendizagem organizacional que se divide em níveis que incluem o desenvolvimento pessoal e organizacional. Em geral, os entrevistados apontaram a gamificação como uma estratégia positiva para as organizações do segmento varejista, oferecendo ganhos pessoais para o funcionário por meio da aprendizagem e do desenvolvimento pessoal. Além disso, eles apontaram a ferramenta como uma nova maneira de motivar e engajar os trabalhadores e equipes e também como estratégia de autoconhecimento.

A gamificação tem sido estudada, majoritariamente, pelas áreas de educação e pesquisa, psicologia, ciências computacionais, comunicação e, em menor escala, gestão e negócios. Dentre as perspectivas de estudos, destaca-se seu impacto como ferramenta educacional de engajamento de estudantes, cognição, aprendizagem e desenvolvimento da comunicação via enigma em ambientes virtuais, engajamento de clientes e gestão de risco, entre outros.

Apresenta-se uma visão da gamificação segundo a percepção de expertises na sua implementação em ambiente organizacional. A partir da análise dos dados, identificou-se a existência de bons resultados para os níveis de análise organizacional e individual. Desse modo os efeitos positivos da gamificação podem ser distribuídos em três dimensões: a organizacional, a de equipe/time e a individual. Assim, destaca-se na dimensão organizacional melhoria na produtividade, na aprendizagem organizacional e nos processos de inovação e update organizacional. Na dimensão equipe/time, notaram-se melhorias no clima organizacional, na comunicação e no trabalho colaborativo. Na dimensão individual, houve desenvolvimento do trabalhador, autonomia, autoestima e maior transparência na relação entre líderes e liderados. 


\section{CONSIDERAÇÕES FINAIS}

A natureza exploratória deste estudo e a amostragem limitam a generalização dos resultados. No entanto, ele sugere caminhos para pesquisas empíricas adicionais que possam estabelecer, de maneira qualitativa, o impacto mais amplo das estratégias de gamificação junto a funcionários e organizações. Dessa forma, sugere-se que futuras pesquisas se estendam após o período de seis meses de implementação da ferramenta, tempo identificado pelos entrevistados como suficiente para mensuração dos resultados. Outra limitação desta pesquisa é a sua abordagem gerencial, entendendo a gamificação como ferramenta para melhorar processos gerenciais. Portanto, sugere-se a pesquisas futuras a adoção de uma abordagem crítica acerca da gamificação.

A principal contribuição do estudo é revelar a potencialidade da estratégia quando utilizada em conjunto com outros elementos, bem como demonstrar a importância de separar didaticamente a análise em dois níveis relevantes para o sucesso da implementação. A maior parte dos entrevistados apontou o sucesso da implementação e manutenção da gamificação como alinhado a outros recursos e estratégias, como palestras de sensibilização, workplace (facebook interno), multiplicadores, gestores engajados, participação dos business partners/RH com atuação em campo, endomarketing etc. Além disso, eles apontaram a importância de a plataforma gamificada fazer sentido para os envolvidos: a alta gestão, os gerentes diretos e os próprios funcionários. Os entrevistados também indicaram a melhora no clima organizacional como um ganho significativo para o engajamento dos funcionários, bem como para a interação entre gestores e equipe.

Cabe ressaltar a importância da alta gestão e dos líderes quanto à disseminação da incorporação da ideia pelo time. Acreditar no resultado facilita o processo, ou seja, empresas voltadas ao desenvolvimento do funcionário que apoiam esses projetos gamificados, por exemplo, têm maior probabilidade de sucesso na implementação já que a credibilidade está instaurada na cultura corporativa.

O apoio da área de recursos humanos e de gestão de mudança revelou-se significativo para a criação de estratégias de maior alcance junto aos trabalhadores (reuniões, campanhas, treinamentos). O preparo de lideranças e multiplicadores também foi apontado como um fator de sucesso para o programa de gamificação na empresa, principalmente para a identificação dos anseios e das motivações do grupo e para a realização de ajustes necessários durante o uso da ferramenta. 


\section{REFERÊNCIAS}

ALVES, F. Gamification: como criar experiências de aprendizagem engajadoras. São Paulo: DVS Editora, 2015.

ARGYRIS, C.; SCHÖN, D. What is an organization that it may learn. In: ARGYRIS, C. (Ed.). Organizational Learning: a theory perspective. Reading: Addison-Wesley, 1978. p. 8-29.

BAJDOR, P.; DRAGOLEA, L. The gamification as a tool to improve risk management in the enterprise. BAJDOR, P.; DRAGOLEA, L. (Ed.). General insights on management: a monograph. 2011. Disponível em: <https://www.researchgate.net/publication/227367892>. Acesso em: 27 out. 2020.

BELTRÃO, K. I.; BARÇANTE, L. C. Adoção de jogo de negócios sob a perspectiva de modelo de excelência da gestão em curso de MBA: análise das avaliações multicritério por pares. Cadernos EBAPE.BR, Rio de Janeiro, v. 17, n. esp., p. 656-672, 2019.

BROUGÈRE, G. Jogo e educação. Porto Alegre: Artmed editora, 1998.

BROUGÈRE, G. Lúdico e educação: novas perspectivas. Linhas Criticas, v. 8, n. 14, p. 5-20, 2002.

BURKE, B. Gamification 2020: What is the future of gamification. Gartner Research, Stamford, Nov. 05, 2012. Disponível em: <https:// www.gartner.com/en/documents/2226015>. Acesso em: 27 out. 2020.

BURKE, B. Gamificar: como a gamificação motiva as pessoas a fazerem coisas extraordinárias. São Paulo: DVS Editora, 2015.

CAILLOIS, R. Os jogos e os homens: a máscara e a vertigem. Petrópolis: Editora Vozes Ltda, 2017.

CASTELLS, M. O poder da identidade (Volume II). 1999. Disponível em: <https://identidadesculturas.files.wordpress. com/2011/05/castellsm-o-poder-da-identidade-cap-1.pdf $>$. Acesso em: 27 out. 2020 .

CHOU, Y. The 8 Core Drives of Gamification (\# 1): Epic Meaning \& Calling. Yu-Kai Chou: Gamification \& Behavioral Design. 2013. Disponível em: <https://yukaichou.com/gamification-study/8core-drives-gamification-1-epic-meaning-calling/>. Acesso em: 27 out. 2020.

D’ÁVILA, C. M. Didática lúdica: saberes pedagógicos e ludicidade no contexto da educação superior. Revista Entreideias: Educação, Cultura e Sociedade, v. 3, n. 2, p. 87-100, 2014.

DEWINTER, J.; KOCUREK, C. A.; NICHOLS, R. Taylorism 2.0: Gamification, Scientific Management and the Capitalist Appropriation of Play. Journal of Gaming \& Virtual Worlds, v. 6, n. 2, p. 109-127, 2014. Disponível em: <https://digitalcommons.tacoma.uw.edu/ias_pub/531>. Acesso em: 27 out. 2020.

DOMÍNGUEZ, A. et al. Gamifying learning experiences: Practical implications and outcomes. Computers and Education, v. 63, p. 380-392, 2013. Disponível em: <https://doi.org/10.1016/j. compedu.2012.12.020>. Acesso em: 27 out. 2020.

FORTUNA, T. Apresentação da Coleção Classicos dos Jogos. In: CAILLOIS, R. Os jogos e os homens: a máscara e a vertigem. Petrópolis: Editora Vozes Ltda, 2017.

GARRATT, B. The learning organisation 15 years on: some personal reflections. The Learning Organization, v. 6, n. 5, p. 202-207, 1999.
GARTNER. Gartner says by 2015, more than 50 percent of organizations that manage innovation processes will gamify those processes. Gartner Research, Stamford, Apr. 02, 2011. Disponível em: <http://www.gartner.com/newsroom/id/1629214>. Acesso em: 27 out. 2020.

GÓMEZ-PABLOS, V. B.; MUÑOZ-REPISO, A. G.-V. Opinión del profesorado hacia proyectos colaborativos con Tecnologías de la Información y Comunicación: un estudio psicométrico. Educação e Pesquisa, v. 45, p. e213768, 2019.

HUIZINGA, J. Homo ludens: o jogo como elemento da cultura (Vol. 4). São Paulo: Editora Perspectiva, 1971.

ISMAIL, S.; VAN GEES, Y.; MALONE, M. S. Organizações exponenciais: por que elas são 10 vezes melhores, mais rápidas e mais baratas que a sua (e o que fazer a respeito). Rio de Janeiro: Alta Books Editora, 2018.

JOHNSON, L.; ADAMS, S.; HAYWOOD, K. The NMC horizon report: 2011- K12 edition. Austin: The New Media Consortium, 2011.

KOSTER, R. Theory of fun for game design. Sebastopol: O'Reilly Media Inc., 2013.

LUCKESI, C. C. Ludicidade e atividades lúdicas: uma abordagem a partir da experiência interna. Educação e Ludicidade, Ensaios 02; Ludicidade o que é mesmo isso? Salvador: FACED/UFBA, 2005. p. 22-60.

MAGUIRE, M.; DELAHUNT, B. Doing a Thematic Analysis: A Practical, Step-by-Step Guide for Learning and Teaching Scholars. All Ireland Journal of Higher Education, v. 9, n. 3, p. 3351-33514, 2017. Disponível em: <http://ojs.aishe.org/index.php/aishe-j/article/view/335>. Acesso em: 27 out. 2020.

MARRAS, J. P.; TOSE, M. Avaliação de desempenho humano. São Paulo: Elsevier Brasil, 2012.

MATURANA, H. R.; VERDEN-ZÖLLER, G. Amar e brincar: Fundamentos esquecidos do humano-Do patriarcado à democracia. São Paulo: Palas Athena, 2004.

MERRIAM, S. B. Qualitative research in practice: Examples for discussion and analysis. San Francisco: Jossey-Bass Inc Pub, 2002.

NOGUEIRA, R. A.; ODELIUS, C. C. Desafios da pesquisa em aprendizagem organizacional. Cadernos EBAPE.BR, Rio de Janeiro, v. 13, n.1, p. 83-102, 2015.

ODELIUS, C. C. et al. Processos de aprendizagem, competências aprendidas, funcionamento, compartilhamento e armazenagem de conhecimentos em grupos de pesquisa. Cadernos EBAPE.BR, Rio de Janeiro, v. 9, n. 1, p. 199-220, 2011.

POOLE, S. et al. Get Your Head in the Game: Using Gamification to Connect with Generation Y in the Classroom. Journal for Excellence in Business Education, v. 3, n.2, p. 274-279, 2014. Disponível em: <http://repository.usfca.edu/ml>. Acesso em: 27 out. 2020.

REVANS, R. W. The origins and growth of action learning. Lund: Studentlitteratur, 1982.

ROBSON, K. et al. Is it all a game? Understanding the principles of gamification. Business Horizons, v. 58, n. 4, p. 411-420, 2015. Disponível em: <https://doi.org/10.1016/j.bushor.2015.03.006>. Acesso em: 27 out. 2020. 
ROBSON, K. et al. Game on: Engaging customers and employees through gamification. Business Horizons, v. 59, n. 1, p. 29-36, 2016. Disponível em: <https://doi.org/10.1016/j.bushor.2015.08.002>. Acesso em: 27 out. 2020.

SANCHEZ, E.; YOUNG, S.; JOUNEAU-SION, C. Classcraft: from gamification to ludicization of classroom management. Education and Information Technologies, v. 22, n. 2, p. 497-513, 2017. Disponível em: <https://doi.org/10.1007/s10639-016-9489-6>. Acesso em: 27 out. 2020.

SANTINHO, C. C. A utilização da gamificação para engajamento de equipes: um estudo de caso sobre a aplicação de um jogo empresarial em uma instituição financeira. 77f. 2018. Dissertação (Mestrado em Administração de Empresas) - Fundação Getulio Vargas, São Paulo, 2018.

SENA, A.; COELHO, D. Gameficação: uma análise das técnicas de engajamento atualmente utilizadas. SBC-ProceedingsofSBGames, Brasília, DF, 02 nov. 2012.

SHPAKOVA, A.; DÖRFLER, V.; MACBRYDE, J. Gamifying the process of innovating. Innovation, v. 22, n. 4, p. 488-502, 2020. Disponível em: <https://doi.org/10.1080/14479338.2019.1642763>. Acesso em: 27 out. 2020.

STRAUSS, A.; CORBIN, J. Basics of qualitative research techniques. Thousand Oaks: Sage Publications, 1998.

THENG, Y.-L. et al. The Use of Videogames, Gamification, and Virtual Environments in the Self-Management of Diabetes: A Systematic
Review of Evidence. Games for Health Journal, v. 4, n. 5, p. 352-361, 2015. Disponível em: <https://doi.org/10.1089/g4h.2014.0114>. Acesso em: 27 out. 2020.

VENTRICE, C. Make their day! Employee recognition that works: Proven ways to boost morale, productivity, and profits. Oakland: Berrett-Koehler Publishers, 2009.

VERSIANI, Â.; FACHIN, R. Avaliando aprendizagem em simulações empresariais. Cadernos EBAPE.BR, Rio de Janeiro, v. 5, n. esp., p. 1-13, 2007.

VIANNA, Y. et al. Gamification, INC: Como reinventar empresas a partir de games. Rio de Janeiro: MJV Press, 2014. Disponível em: <http://www.livrogamification.com.br>. Acesso em: 27 out. 2020.

WANG, C. L.; AHMED, P. K. Organisational learning: a critical review. The Learning Organization, v. 10, n. 1, p. 8-17, 2003.

WATSON, W. R.; MONG, C. J.; HARRIS, C. A. A case study of the in-class use of a video game for teaching high school history. Computers and Education, v. 56, n. 2, p. 466-474, 2011. Disponível em: <https://doi. org/10.1016/j.compedu.2010.09.007>. Acesso em: 27 out. 2020.

WERBACH, K.; HUNTER, D. For the win: How game thinking can revolutionize your business. Washington, DC: Wharton Digital Press, 2012.

ZICHERMANN, G.; CUNNINGHAM, C. Gamification by design: Implementing game mechanics in web and mobile apps. Sebastopol: O’Reilly Media Inc., 2011.

Soraia Finamor Neidenbach

ORCID: https://orcid.org/0000-0003-4894-2446

Mestre em Administração de empresas pela Fundação Getulio Vargas (FGV EAESP), Mestrado Profissional em Gestão para Competitividade (MPGC), São Paulo - SP, Brasil. E-mail: sfinamor@hotmail.com

Vanessa Martines Cepellos

ORCID: https://orcid.org/0000-0001-6707-9751

Professora na Fundação Getulio Vargas pela Escola de Administração de Empresas de São Paulo (FGV EAESP), Mestrado Profissional em Gestão para Competitividade (MPGC), São Paulo - SP, Brasil. E-mail: vanessa.cepellos@fgv.br 